\title{
Environmental temperature variation influences fitness trade-offs and tolerance in a fish-tapeworm association
}

\author{
Frederik Franke, Sophie A. O. Armitage, Megan A. M. Kutzer, Joachim Kurtz and Jörn P. Scharsack*
}

\begin{abstract}
Background: Increasing temperatures are predicted to strongly impact host-parasite interactions, but empirical tests are rare. Host species that are naturally exposed to a broad temperature spectrum offer the possibility to investigate the effects of elevated temperatures on hosts and parasites. Using three-spined sticklebacks, Gasterosteus aculeatus L., and tapeworms, Schistocephalus solidus (Müller, 1776), originating from a cold and a warm water site of a volcanic lake, we subjected sympatric and allopatric host-parasite combinations to cold and warm conditions in a fully crossed design. We predicted that warm temperatures would promote the development of the parasites, while the hosts might benefit from cooler temperatures. We further expected adaptations to the local temperature and mutual adaptations of local host-parasite pairs.

Results: Overall, S. solidus parasites grew faster at warm temperatures and stickleback hosts at cold temperatures. On a finer scale, we observed that parasites were able to exploit their hosts more efficiently at the parasite's temperature of origin. In contrast, host tolerance towards parasite infection was higher when sticklebacks were infected with parasites at the parasite's 'foreign' temperature. Cold-origin sticklebacks tended to grow faster and parasite infection induced a stronger immune response.
\end{abstract}

Conclusions: Our results suggest that increasing environmental temperatures promote the parasite rather than the host and that host tolerance is dependent on the interaction between parasite infection and temperature. Sticklebacks might use tolerance mechanisms towards parasite infection in combination with their high plasticity towards temperature changes to cope with increasing parasite infection pressures and rising temperatures.

Keywords: Host-parasite interaction, Fitness, Tolerance, Environment, Temperature, Gasterosteus aculeatus, Schistocephalus solidus

\section{Background}

Both hosts and parasites are under selection pressure to optimise their fitness in response to their local host or parasite partner and at the same time to the local environmental conditions. Recent studies suggest that host-parasite dynamics depend on interactions with environmental factors [1-3], which eventually leads to local adaptation as a consequence of their coevolutionary arms race [4, 5]. Accordingly, changing environments interfere with host-parasite dynamics and a central question is, how are host and parasite fitness influenced by

\footnotetext{
* Correspondence: joern.scharsack@uni-muenster.de Institute for Evolution and Biodiversity, University of Münster, Hüfferstrasse 1, 48149 Münster, Germany
}

(c) The Author(s). 2017 Open Access This article is distributed under the terms of the Creative Commons Attribution 4.0 International License (http://creativecommons.org/licenses/by/4.0/), which permits unrestricted use, distribution, and reproduction in any medium, provided you give appropriate credit to the original author(s) and the source, provide a link to the Creative Commons license, and indicate if changes were made. The Creative Commons Public Domain Dedication waiver (http://creativecommons.org/publicdomain/zero/1.0/) applies to the data made available in this article, unless otherwise stated.

environmental variation? Selection pressures might force hosts and parasites to adapt to local environmental conditions, but might also trigger the ability to respond plastically to changing environments. Here we elucidate the interplay between hosts, parasites and the environment, by comparing sympatric and allopatric host-parasite combinations, whilst at the same time manipulating experimental temperature, a highly influential environmental condition, particularly for ectothermic hosts.

We used the three-spined stickleback, Gasterosteus aculeatus L., and its macroparasite tapeworm Schistocephalus solidus (Müller, 1776) originating from a cold and a warm site of the Icelandic volcanic lake Mývatn. Millet et al. [6] investigated the genetic structure of the stickleback population of Lake Mývatn and demonstrated that 
the sticklebacks from their eleven sampling sites (including cold and warm fed sites) showed little genetic variation, but they exhibited significant phenotypic differences. Interestingly, a higher prevalence (26\%) of S. solidus was detected in sticklebacks from warmwater sites of Lake Mývatn, compared to a lower prevalence $(7 \%)$ in sticklebacks from cold-water sites of the lake [7]. This could have been caused by biotic factors, e.g. the abundance of copepods, the first intermediate host of S. solidus, but might also be a direct effect of temperature.

The cestode S. solidus has a complex life-cycle with copepods as the first host and three-spined sticklebacks as the obligatory and specific second intermediate host. S. solidus acquires most of its resources from the stickleback resulting in substantially decreased host reproductive ability, e.g. by preventing females from spawning [8-12], before it manipulates the stickleback's behaviour to increase transmission to its final host, a piscivorous bird [13, 14]. The weight of the mature $S$. solidus is positively correlated with parasite fecundity and is therefore a well suited fitness correlate $[15,16]$. Given the severe loss of fitness for infected stickleback, the selection pressure imposed by $S$. solidus must be high. It has been suggested that sticklebacks in populations with high infection pressure become locally adapted and are more resistant, i.e. have lower infection rates and more efficiently constrain $S$. solidus growth $[17,18]$. On the other hand, S. solidus seems to adapt to the increased resistance of local hosts and become more virulent, i.e. increased infection success and host exploitation rates $[17,18]$.

As an alternative to investment in resistance measures to depress parasite growth, hosts may also use a tolerance strategy, allowing them to maximise fitness whilst being infected. Tolerance is the ability of hosts to limit the damage caused by a given parasite load [19]. Tolerance is measured at the population level by plotting individual host fitness against individual parasite loads, the reaction norm giving the relationship between the two parameters describes tolerance. For example, a population with a positive or shallow negative reaction norm is more tolerant, i.e. better at minimising the negative fitness effect of an increasing infection intensity, than a population with a steeper negative slope $[19,20]$. A number of studies have shown that hosts use tolerance to mitigate fitness losses during infections with microparasites [19, 21-24]. Given that macroparasites can also dramatically reduce host fitness $[12,25,26]$, tolerance might be expected to be an important host strategy [27]. Indeed, in an unmanaged Soay sheep population, individuals that were more tolerant to gastrointestinal nematodes, had higher lifetime breeding success [28]. In our study, we use stickleback growth rate as a measure for health tolerance and gonad weight was employed to estimate fecundity tolerance. Both parameters are hypothesised to be affected by the growing $S$. solidus since the parasite drains substantial amounts of nutrients from its host $[8,10,11]$. Although local adaptation for resistance has been shown, evidence of local adaptation for tolerance has not been found to date [21, 22, 24]. In a mesocosm experiment, lake and stream stickleback ecotypes were similarly non-tolerant to an ectoparasite (Gyrodactylus sp.), but elevated nutrient load tended to increase tolerance of stream sticklebacks [29], which might suggest that tolerance varies according to environmental conditions.

Adaptation of sticklebacks to local temperatures was suggested by Dittmar et al. [30], who observed stronger immunological disorders and higher mortality in F1 sticklebacks from a brook compared to F1 sticklebacks from a pond during experimental exposure to a heat wave of up to $28{ }^{\circ} \mathrm{C}$. Furthermore, studies with threespined sticklebacks from a marine origin, which were adapted to cold and warm conditions in the laboratory for one generation, illustrated that cold adapted sticklebacks had offspring with faster growth compared to warm adapted sticklebacks, which suggests considerable transgenerational plasticity in stickleback temperature adaptation [31-33].

It is predicted that increasing temperatures will significantly alter host-parasite interactions, especially in multi-host parasite life-cycles, since the addition of every further host/parasite larval stage increases the possibility of responses [34]. Temperature affects host-parasite interactions through various pathways, e.g. it might alter host food consumption and thereby change the risk of becoming exposed to trophically transmitted parasites [35]. Furthermore, temperature plays a key role in determining the efficacy of the immune system - the host's most important physiological barrier against parasitation $[30,36,37]$. In this respect it has been shown that increasing temperature coincided with a higher output of trematode cercariae [38-40] and increased infectivity of metacercariae, while the survival of amphipod hosts decreased [41]. Other studies have observed faster lifecycle completion rates at warmer temperatures in nematodes [42] and acanthocephalans [43], which increases the parasite infection pressure on their hosts. A few lines of evidence suggest that higher temperatures can be detrimental to infected sticklebacks, but beneficial to the parasites; for example, an enclosure experiment during the 2003 European heat wave found that moribund sticklebacks had higher parasite burdens compared to survivors [44]; sticklebacks showed lower growth rates and higher mortality after infection with Vibrio bacteria at $21{ }^{\circ} \mathrm{C}$ compared to $17{ }^{\circ} \mathrm{C}$ [45], and S. solidus had a faster growth rate at $20{ }^{\circ} \mathrm{C}$ compared to $15{ }^{\circ} \mathrm{C}$ [46]. 
In the present study, we used the offspring of sticklebacks and S. solidus collected from warm and cold sites in Lake Mývatn to investigate potential mutual adaptations of local host-parasite pairs and their adaptations to the local temperature regimes. We exposed sticklebacks from both sites to sympatric and allopatric S. solidus and to a cold and a warm experimental temperature, in a fully crossed experimental design. We analysed host immune traits as well as host and parasite body condition parameters, which served as fitness estimates. We predicted that parasites might gain higher fitness at elevated temperatures, while the stickleback hosts might benefit from lower temperatures. We further hypothesised that both hosts and parasites would be adapted to their local temperature regimes, i.e. that cold-origin hosts and parasites would perform better under cold conditions compared to warm conditions and vice versa. Further, if local adaptation exists, hosts and parasites might exhibit mutual adaptations to the genotype of their local counterparts.

\section{Methods}

\section{Study lake and sampling}

The sticklebacks and parasites originated from Lake Mývatn in northern Iceland, which was formed by volcanic eruptions 2,300 years ago (about 2,300 stickleback generations), and is fed by cold (around $5{ }^{\circ} \mathrm{C}$ ), but also warm (up to $30{ }^{\circ} \mathrm{C}$ ) groundwater inputs [7]. Sticklebacks in breeding condition and S. solidus parasitized sticklebacks were collected with minnow traps at a cold $\left(65^{\circ} 39^{\prime} 13.38^{\prime \prime} \mathrm{N}, 16^{\circ} 57^{\prime} 45.27^{\prime \prime} \mathrm{W}\right)$ and a warm $\left(65^{\circ} 37^{\prime}\right.$ $41.66^{\prime \prime} \mathrm{N}, 16^{\circ} 55^{\prime} 16.97^{\prime \prime} \mathrm{W}$ ) water site (linear distance $3.4 \mathrm{~km}$ ) in June 2014. The sperm of one male stickleback were used to in vitro fertilize [47] the egg clutch of a single female stickleback and the fertilized clutches (offspring from one clutch are below referred to as a 'family') were then transferred to tubes with $40 \mathrm{ml}$ aerated tap water. The body cavities of infected sticklebacks were opened, the parasites were removed aseptically, weighed and transferred to individual tubes with $10 \mathrm{ml}$ cell culture medium (MEM, Gibco, Thermo Fisher Scientific, USA). Schistocephalus solidus larvae and fertilized stickleback egg clutches were transported to our laboratory in Münster, Germany. At each sampling site the water temperature was recorded from June 2014 for twelve months (HOBO Water Temp Pro v2, Onset, USA). The average temperature at the cold sampling site was $4.8{ }^{\circ} \mathrm{C}$ (min: $0{ }^{\circ} \mathrm{C}$, max: $18.8{ }^{\circ} \mathrm{C}$ ), and $18.4{ }^{\circ} \mathrm{C}\left(\min : 10.5{ }^{\circ} \mathrm{C}\right.$, max: $23.3^{\circ} \mathrm{C}$ ) at the warm site (see Additional file 1: Figure S1 for annual temperature fluctuations).

\section{Animal husbandry}

After initial feeding with Artemia salina nauplii and frozen plankton, the sticklebacks were fed ad libitum with chironomids and kept separated by families in $14 \mathrm{l}$ tanks with recirculating tap water at $16{ }^{\circ} \mathrm{C}$ and a light/dark cycle of 14/10 h. For egg production, parasites were size matched to increase the probability of outcrossing [48] and bred in vitro as described previously $[49,50]$. Briefly, parasite eggs were washed and stored at $4{ }^{\circ} \mathrm{C}$ in the dark. For larval development, S. solidus eggs were incubated for 3 weeks at $20{ }^{\circ} \mathrm{C}$ in the dark. To initiate hatching, eggs were illuminated for $3 \mathrm{~h}$ followed by $8 \mathrm{~h}$ darkness overnight, and at least $2 \mathrm{~h}$ illumination the next morning. Hatched coracidia were transferred singly to wells of a 24-well plate, with one copepod (Macrocyclops albidus (Jurine)) each in $2 \mathrm{ml}$ tap water. After 2 weeks, the copepods were checked under a microscope for the presence of S. solidus larvae. Collection, transport of and experimentation with animals in the present study was done in accordance with the local veterinary and animal welfare authorities under the project number 87-51.04.2010.A297.

\section{Experimental design}

Laboratory reared sticklebacks from the cold and the warm origin were exposed to uninfected copepods (sham-exposed) or to copepods infected with a single $S$. solidus from either the cold or the warm origin. The infection was allowed to develop for 3 weeks, to avoid temperature effects on the infection rates, after this time half of the sticklebacks were adjusted to the cold experimental temperature and half to the warm experimental temperature. It is common that not all S. solidus exposed sticklebacks become infected $[18,37]$. Therefore, the parasite-exposed group was further divided into 'exposed but not infected' and 'infected' sticklebacks. Together with the sham-exposed groups, this resulted in ten treatment groups per experimental temperature; the $\mathrm{x}$-axis legend in Fig. 1 details all of the experimental groups.

\section{Parasite exposure}

In total, 432 adolescent sticklebacks (216 from the cold and 216 from the warm origin) were taken from 24 families (12 families per origin) and allocated in a balanced design to experimental treatments. Nine sticklebacks per origin, 18 in total, were placed together in 141 tanks. Sticklebacks from each origin were allocated to sham exposure and parasite exposure (cold/warm parasite origin) in a way that each of the ten exposure treatments was represented in every tank at least once. For the parasite exposure we used copepods that were singly infected with $S$. solidus larvae from 24 families (12 families per origin) in a balanced design. Experimental tanks were organized in two identical sets for the two temperature treatments.

Three weeks prior to copepod exposure, the sticklebacks were marked with Visible Implant Elastomer Tags (Northwest Marine Technologies, USA) and placed in 


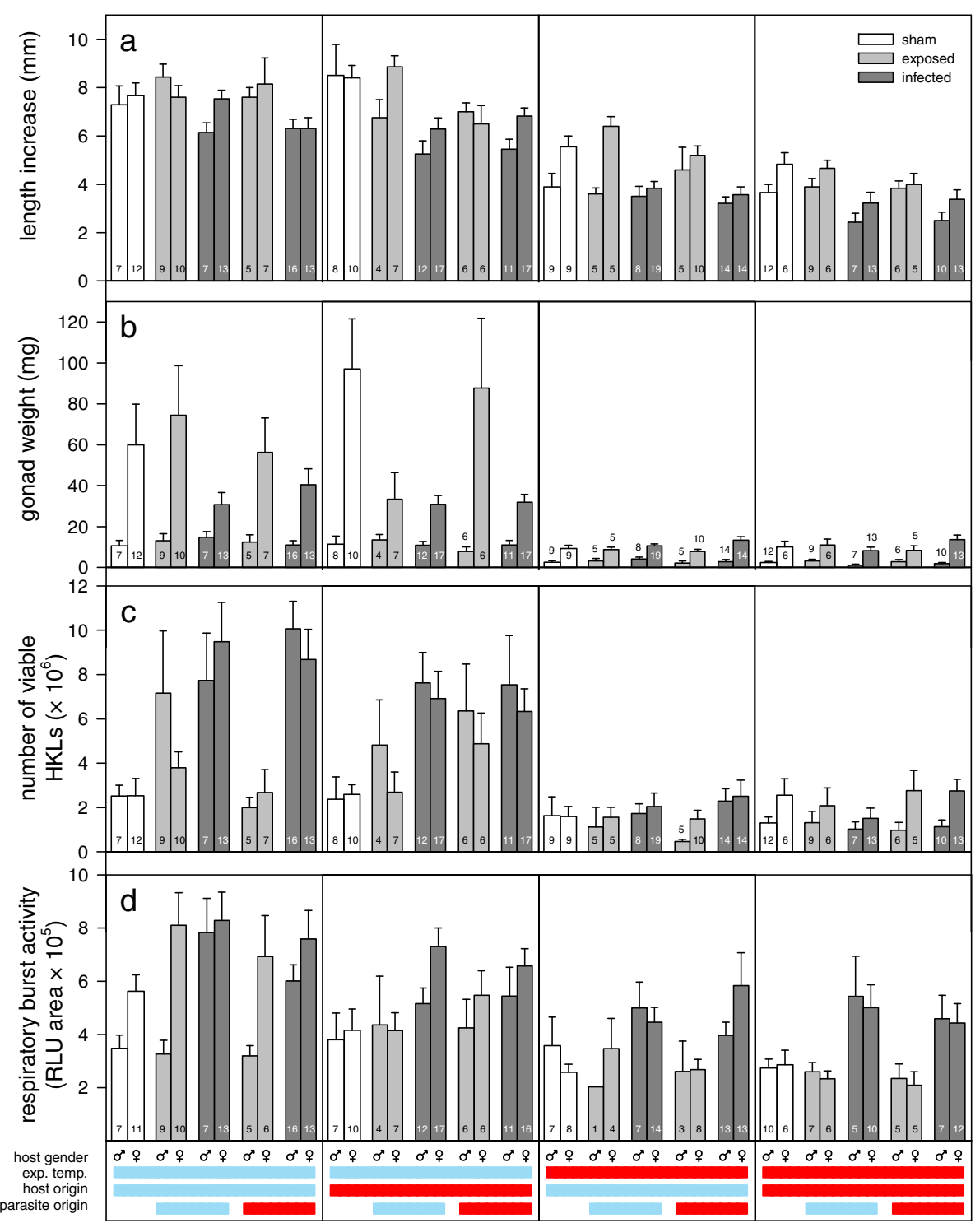

Fig. 1 Host responses to temperature variation and S. solidus infection. a Host length increase. b Gonad weight. c Total number of viable head-kidney leukocytes (HKLs) per fish. $\mathbf{d}$ Respiratory burst activity. The cold experimental temperature $\left(13^{\circ} \mathrm{C}\right)$ and the cold host and parasite origin are indicated by the blue bars and the warm experimental temperature $\left(24^{\circ} \mathrm{C}\right)$ and the warm host and parasite origin by the red bars. Sample sizes are shown inside the bars and bars represent means \pm SE from sham-exposed (sham), exposed but not infected (exposed) and infected sticklebacks

the experimental tanks. Subsequently, all tanks were adjusted from $16{ }^{\circ} \mathrm{C}$ to $18{ }^{\circ} \mathrm{C}\left(\Delta T 0.3^{\circ} \mathrm{C}\right.$ per day). This resulted in a starting temperature that was approximately mid-way between the two experimental temperatures $\left(13\right.$ and $\left.24{ }^{\circ} \mathrm{C}\right)$ and it was also the same temperature as previous studies testing stickleback immune activity [30]. The sticklebacks were starved $72 \mathrm{~h}$ prior to copepod exposure and $24 \mathrm{~h}$ before exposure they were measured to the nearest $\mathrm{mm}$ (infection length) and transferred to individual glass jars with $300 \mathrm{ml}$ tank water. The following day, 80 sticklebacks ( 40 per origin) were given one uninfected copepod to eat and 352 sticklebacks (176 per origin) were given one copepod infected with one $S$. solidus ( $88 \mathrm{~S}$. solidus infected copepods per host origin/ parasite origin combination). The next day water from each jar was sieved and screened to confirm ingestion of copepods and the sticklebacks were returned to their experimental tanks. To minimize temperature effects on the infection rate, exposed fish were kept at $18{ }^{\circ} \mathrm{C}$, to give the parasites time to establish in the body cavities of the sticklebacks [37]. Thereafter, the water temperature was changed to $13{ }^{\circ} \mathrm{C}\left(\Delta T 0.8{ }^{\circ} \mathrm{C}\right.$ per day) for half of the experimental tanks and to $24{ }^{\circ} \mathrm{C}\left(\Delta T 1{ }^{\circ} \mathrm{C}\right.$ per day) for the other half. With the lower temperature, 
$13{ }^{\circ} \mathrm{C}$, we intended to match a range that still permits the growth of hosts and parasites. By using $24{ }^{\circ} \mathrm{C}$ we aimed to challenge the hosts and parasites physiological capabilities.

\section{Dissection of experimental sticklebacks}

The sticklebacks were dissected 56-58 days after copepod exposure when we expected that the parasites had achieved sexual maturity, i.e. exceeded the $50 \mathrm{mg}$ threshold [51], at both experimental temperatures. They were anesthetised with MS-222 (Sigma-Aldrich, USA) and measured to the nearest $\mathrm{mm}$ (dissection length). Stickleback length increase was calculated by subtracting the infection length from the dissection length and served as a measure of stickleback fitness (health). The sticklebacks were decapitated and the body cavities were opened. To measure host immune parameters, the right head kidney was removed aseptically and transferred to $40 \mu \mathrm{m}$ cell strainers (Falcon, BD, USA) placed in Petri dishes (ø $35 \mathrm{~mm}$ ) with $1 \mathrm{ml}$ heparinized $\left(2 \times 10^{4} \mathrm{IU} \mathrm{1}^{-1}\right.$; Sigma-Aldrich) R-90 medium (RPMI-1640 with 10 mmol $1^{-1}$ HEPES (both Gibco, Thermo Fisher Scientific, USA) and 10\% (v/v) distilled water) on ice. The gender of the sticklebacks was recorded, the gonads were removed and the gonad weight was determined to the nearest $0.1 \mathrm{mg}$ as a measure of stickleback fitness (fecundity). Subsequently, the tapeworms were removed from the infected sticklebacks and the parasite weight was determined to the nearest $\mathrm{mg}$ as a measure of parasite fitness $[15,16]$.

\section{Leukocyte isolation}

Stickleback head kidney leukocytes (HKLs) were isolated as described in Scharsack et al. [52]. Briefly, cells and media were kept on ice, single cell suspensions of HKLs were prepared by forcing the tissues through the strainers with a syringe plunger. The HKLs were washed once with heparinized R-90 $\left(600 \times g, 4{ }^{\circ} \mathrm{C}, 5 \mathrm{~min}\right)$, once with pure R-90, and resuspended in $500 \mu \mathrm{l}$ R-90. Cell numbers were determined by means of flow cytometry and adjusted to $1.25 \times 10^{6}$ viable HKLs $\mathrm{ml}^{-1}$.

\section{Immune assays}

Sticklebacks increase their numbers of head kidney leukocytes (HKLs) and their respiratory burst activity, one of the most important effector mechanisms of cellular innate immunity, during S. solidus infection [18, 53]. With the present study, we wanted to test whether temperature alters the leukocyte responses to $S$. solidus infection. Total numbers of viable HKLs per fish were determined by means of flow cytometry (FACSCanto II, $\mathrm{BD}$, USA) with the standard cell dilution assay [54] as described by Scharsack et al. [53]. Briefly, HKL suspensions were measured with propidium iodide $\left(2 \mathrm{mg} \mathrm{l}^{-1}\right.$; Sigma-Aldrich) and green fluorescent reference particles
(Fluoresbrite YG Carboxylate Microspheres $4.5 \mu \mathrm{m}$, Polysciences, USA). Flow cytometric data were analysed with the FacsDiva software (version 6.1.2, BD). Dead cells (propidium iodide positive) and cellular debris (low light scatter characteristics) were excluded and viable HKLs were identified according to their characteristic scatter profiles.

The respiratory burst activity of HKLs was measured in a lucigenin-enhanced chemiluminescence assay [55] modified by Kurtz et al. [56]. Viable HKLs, $1 \times 10^{5}$ per well of white 96-well microplates (Nunc, Thermo Fisher Scientific, USA), were pre-incubated with lucigenin (0.28 $\mathrm{g} \mathrm{l}^{-1}$; Sigma-Aldrich) for $30 \mathrm{~min}$ and respiratory burst was induced by the addition of zymosan $\left(0.75 \mathrm{~g} \mathrm{l}^{-1}\right.$; Sigma-Aldrich). Relative luminescence units (RLUs) of individual wells were measured for $3 \mathrm{~h}$ at $20{ }^{\circ} \mathrm{C}$ with an Infinite 200 microplate reader (Tecan, Männedorf, Switzerland). For data analyses, the area under the kinetic curve (RLU area) was determined using the Magellan 6.5 software (Tecan).

\section{Statistical analyses}

We first tested the effect of experimental temperature (13 or $24{ }^{\circ} \mathrm{C}$ ), host origin (cold or warm), parasite origin (cold or warm) and host gender (male or female) on the probability of sticklebacks becoming infected by $S$. solidus using a generalized linear model (GLM) in a binary logistic regression.

The host response variables (length increase, gonad weight, number of head-kidney leukocytes (HKLs) and respiratory burst activity) were analysed in two separate subsets since sham-exposed sticklebacks had missing values for parasite origin: (i) data from all uninfected sticklebacks (sham-exposed and exposed but not infected); and (ii) data from all parasite exposed sticklebacks (exposed but not infected and infected). After visual inspection of the response variable distributions, all response variables were Box-Cox transformed. Using linear models (LMs), we tested the effects of experimental temperature, host gender, host infection status (sham-exposed or exposed but not infected and exposed but not infected or infected) and host origin on each response variable (Additional file 1: Table S1). Parasite origin was only included in models with data from parasite-exposed sticklebacks. The response variable parasite weight was tested with the above factors, but excluding host infection status. We included all possible two- and three-way interactions in all models. Host dissection length was included as a covariate in models that depended on host size (i.e. host length increase, host gonad weight, number of HKLs and parasite weight). Sequential Bonferroni corrected post-hoc comparisons were computed to investigate significant interaction effects (Additional file 1: Table S2). 
To test whether host tolerance varied according to our experimental treatments, we analysed two different response variables: host length increase (indicating health tolerance), and gonad weight (indicating fecundity tolerance). Using LMs, we tested whether there was an effect of experimental temperature, host origin, parasite origin or host gender on health or fecundity tolerance (Additional file 1: Table S3). Parasite weight was included as a continuous predictor variable in each model and all possible interactions were included up to three-way. A significant interaction between any of the factors and parasite weight would reveal that this factor affects host tolerance $[19,24]$. Tolerance is illustrated as the slope of the relationship between host health or fecundity, and parasite weight, where steeper positive slopes indicate greater tolerance. Host dissection length was included as a covariate in both models to account for the dependency of host length increase and host gonad weight on the host dissection length. After accounting for this, the slopes were positive because larger fish generally have larger parasites. In further models we replaced host and parasite origin with a factor that described whether the combination of host and parasite was sympatric or allopatric. Where we observed significant differences in host tolerance, we compared the slopes of the regressions by sequential Bonferroni corrected, pairwise comparisons using the/ LMATRIX subcommand.

We considered including the quadratic term of parasite weight into our tolerance models to account for non-linear relationships [19-21, 24, 27, 57]. Only including the linear term for parasite weight plus all other factors and interactions up to three-way, meant testing the effects of 25 parameters in total. However, adding a quadratic term for parasite weight and all subsequent interactions would have resulted in models with up to 37 parameters, which would clearly overfit our models [58] when considering that we had 204 observations, i.e. infected fish, for the tolerance models. Thus, we decided to restrict the models to linear relationships in order to avoid model-overfitting.

Whenever we found significant interaction terms in any of the models, we checked the underlying main effects and lower level interactions for validity by simple effects tests before interpretation. A Chi-square test of independence was calculated comparing the frequency of mortality in sticklebacks kept at 13 and $24{ }^{\circ} \mathrm{C}$. All statistical analyses were performed in SPSS Statistics version 23 (IBM, USA).

\section{Results}

\section{Sample size}

From the 432 sticklebacks used for the experiment, 50 were excluded from data analysis: 11 for technical reasons (see Additional file 1: Table S4 for details) and 39 fish died (16 died prior to temperature change, two at $13{ }^{\circ} \mathrm{C}$ and 21 at $24{ }^{\circ} \mathrm{C}$ ). The mortality was significantly higher at $24{ }^{\circ} \mathrm{C}$ compared to $13^{\circ} \mathrm{C}\left(\chi_{(1, N}^{2}=405\right)=15.96$, $P<0.001)$. Apart from that, mortality did not depend on any of the other experimental variables (see Additional file 1: Table S5 for details). Due to low numbers of head kidney leukocytes (HKLs) an additional 38 sticklebacks could not be used in the respiratory burst assay (see Fig. 1 for detailed sample sizes).

\section{Schistocephalus solidus infection and parasite fitness}

Of the 309 sticklebacks exposed to S. solidus and used for data analysis, 204 became infected (mean infected: 67\%; range across treatment groups: 51 to $81 \%$ infected). The infection rate did not significantly depend on any of the experimental variables. Parasites grew significantly larger in their hosts at $24{ }^{\circ} \mathrm{C}$ compared to $13{ }^{\circ} \mathrm{C}$ $\left(F_{(1,188)}=266.95, P<0.001\right.$; Fig. 2$)$ and parasite growth also depended on host gender $\left(F_{(1,188)}=7.08, P=0.008\right)$, but neither parasite nor host origin had a significant influence on parasite growth (Additional file 1: Table S1).

\section{Host fitness}

To estimate stickleback fitness, we measured their length increase (Fig. 1a) and gonad weight (Fig. 1b). The sticklebacks grew faster at $13{ }^{\circ} \mathrm{C}$ compared to $24{ }^{\circ} \mathrm{C}$ (all uninfected: $F_{(1,162)}=158.12, P<0.001$ and all exposed: $\left.F_{(1,282)}=265.50, P<0.001\right)$. Female sticklebacks had a greater length increase than males (all exposed: $F_{(1,282)}=$ 7.68, $P=0.006)$ or grew faster than males at the warm experimental temperature (all uninfected: experimental temperature $\times$ host gender, $\left.\quad F_{(1,162)}=5.25, \quad P=0.023\right)$. Schistocephalus solidus infection significantly decreased

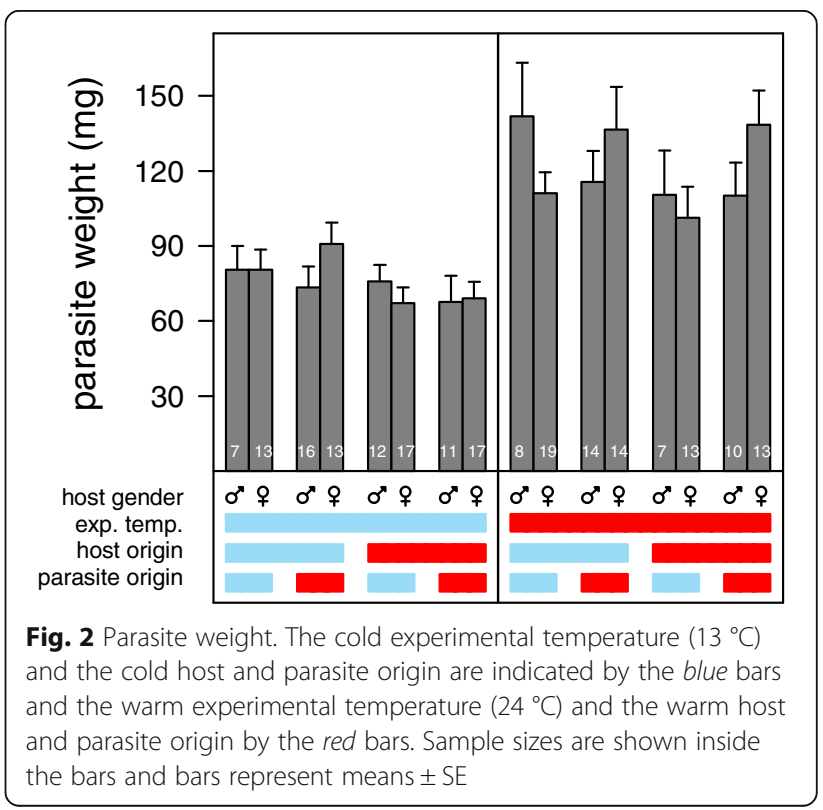


host growth (all exposed: $F_{(1,282)}=51.43, \quad P<0.001$ ). Among S. solidus exposed sticklebacks, cold-origin sticklebacks grew faster than warm-origin ones (i) when exposed but not infected with parasites from the warm origin and (ii) when infected with parasites from the cold origin, which resulted in a significant three way interaction (Fig. 3a; all exposed: host infection status $\times$ host origin $\times$ parasite origin, $F_{(1,282)}=5.40, P=0.021$ ).

Similarly, to host growth, the sticklebacks developed larger gonads at $13{ }^{\circ} \mathrm{C}$ compared to $24{ }^{\circ} \mathrm{C}$ (all uninfected: $F_{(1,162)}=66.31, \quad P<0.001$ and all exposed: $F_{(1,282)}=$ 169.56, $P<0.001)$. The infection with $S$. solidus affected the gonad development of female but not of male sticklebacks (Additional file 1: Table S1). At $13{ }^{\circ} \mathrm{C}$, infected female stickleback had smaller gonads than uninfected ones, but this was inverted at $24{ }^{\circ} \mathrm{C}$ resulting in higher gonad weights in infected compared to
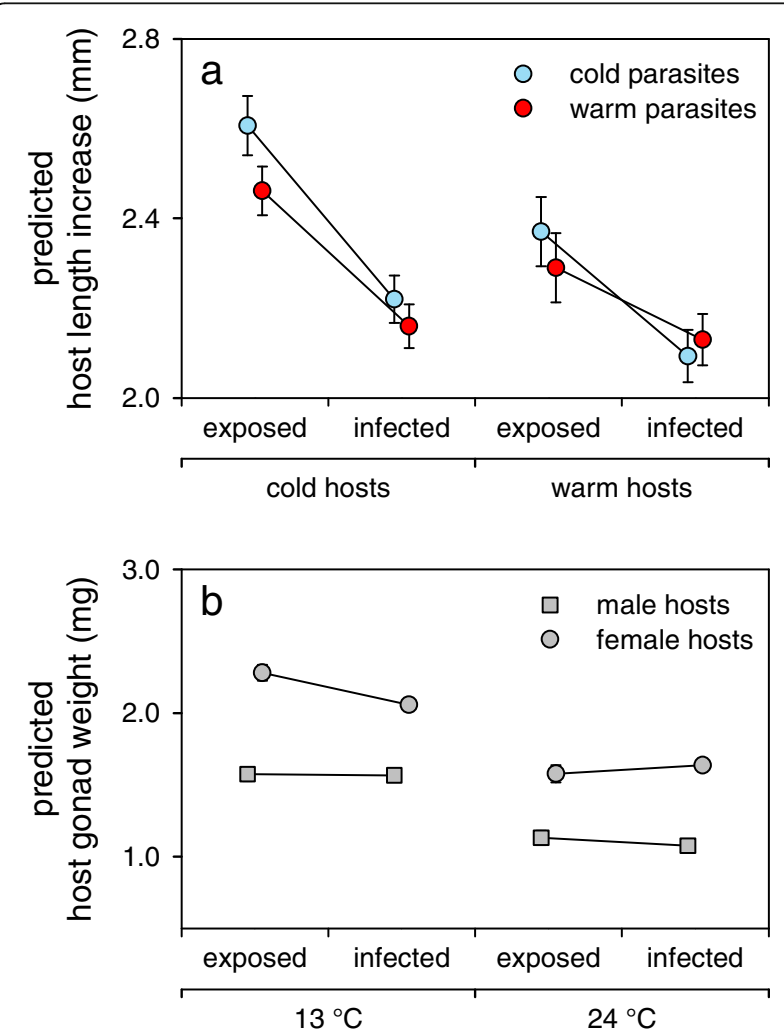

Fig. 3 Three-way interactions explaining variation in host body condition. a The significant interaction $\left(F_{(1,282)}=5.40, P=0.021\right)$ for host length increase between host infection status (exposed but not infected (exposed) or infected), host origin (cold or warm) and parasite origin (cold or warm). b The significant interaction $\left(F_{(1,282)}=9.95\right.$, $P=0.002)$ for host gonad weight between host infection status (exposed but not infected or infected), experimental temperature (13 or $24^{\circ} \mathrm{C}$ ) and host gender (male or female). Means \pm SE (they are too small to be visible in Fig. $3 \mathrm{~b}$ ) are model-predictions from Box-Cox transformed data and not congruent with the values from Fig. 1a, b. For P-values of post-hoc comparisons between groups see Additional file 1: Table S2 exposed but not infected females (Fig. 3b; all exposed: experimental temperature $\times$ host infection status $\times$ host gender, $\left.F_{(1,282)}=9.95, P=0.002\right)$. However, the effects of $S$. solidus on female gonad weight at $24{ }^{\circ} \mathrm{C}$ were only marginal compared to the prominent differences between temperature treatments.

\section{Host immunity}

We counted the number of viable head-kidney leukocytes (HKLs; Fig. 1c) and measured their respiratory burst activity (Fig. 1d) to estimate host immune activity. Interestingly, the numbers of HKLs were increased at $13{ }^{\circ} \mathrm{C}$ in exposed but not infected sticklebacks compared to sham-exposed sticklebacks kept at the same temperature and compared to exposed but not infected sticklebacks kept at $24{ }^{\circ} \mathrm{C}$ (Fig. 4a; all uninfected: experimental temperature $\times$ host infection status, $F_{(1,162)}=7.86$, $P=0.006)$. We collected significantly more HKLs from infected than from exposed but not infected sticklebacks (all exposed: $\left.F_{(1,282)}=43.38, P<0.001\right)$, although this difference was more prominent in cold-origin compared to warm-origin sticklebacks (Fig. 4b; all exposed: host infection status $\times$ host origin, $\left.F_{(1,282)}=14.32, P<0.001\right)$.

The respiratory burst activity was higher in HKLs from sticklebacks kept at $13{ }^{\circ} \mathrm{C}$ compared to $24{ }^{\circ} \mathrm{C}$ (all uninfected: $F_{(1,143)}=34.62, P<0.001$ and all exposed: $\left.F_{(1,252)}=51.31, P<0.001\right)$ and females had higher respiratory burst activity than males at $13{ }^{\circ} \mathrm{C}$ but not at $24{ }^{\circ} \mathrm{C}$ (all uninfected: experimental temperature $\times$ host gender, $F_{(1,143)}=5.93, P=0.016$ and all exposed: experimental temperature $\times$ host gender, $\left.F_{(1,252)}=5.33, P=0.022\right)$. The respiratory burst activity of HKLs from infected sticklebacks was strongly increased in comparison to their exposed but not infected conspecifics (all exposed: $F_{(1,252)}=$ $51.87, P<0.001)$.
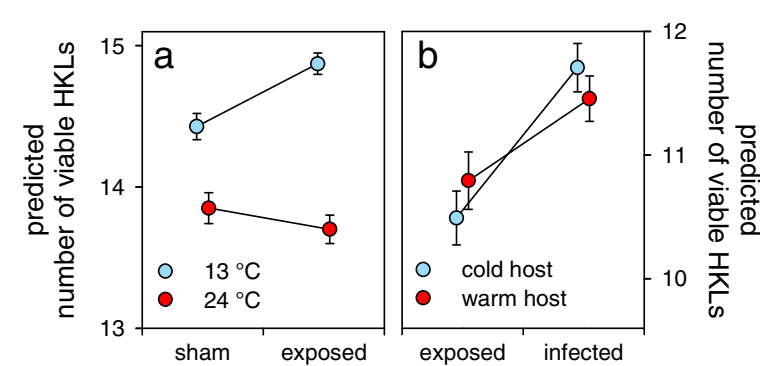

Fig. 4 Two-way interactions explaining variation in head kidney leukocyte $(H K L)$ numbers. a The significant interaction $\left(F_{(1,162)}=7.86\right.$, $P=0.006$ ) between host infection status (sham-exposed (sham) or exposed but not infected (exposed)) and experimental temperature $\left(13\right.$ or $\left.24^{\circ} \mathrm{C}\right)$. b The significant interaction $\left(F_{(1,282)}=14.32, P<0.001\right)$ between host infection status (exposed but not infected or infected) and host origin (cold or warm). Means \pm SE are model-predictions from Box-Cox transformed data and not congruent with the values from Fig. 1c. For $P$-values of post-hoc comparisons between groups see Additional file 1: Table S2 


\section{Host tolerance}

When we examined host health tolerance towards $S$. solidus infection as the relationship between host length increase and parasite weight, we observed a significant interaction between experimental temperature, parasite origin and parasite weight (Fig. $5 ; F_{(1,177)}=$ 6.72, $P=0.010)$. This indicates that health tolerance was differentially affected by experimental temperature and parasite origin. Sticklebacks from the cold experimental temperature, infected with $S$. solidus from the warm origin (upper red line in Fig. 5) were more tolerant when compared to (i) sticklebacks infected with cold-origin parasites at $24{ }^{\circ} \mathrm{C}$ (lower blue line; $F_{(1,196)}$ $=7.36, P=0.022$ ), (ii) sticklebacks infected with coldorigin parasites at $13{ }^{\circ} \mathrm{C}$ (upper blue line; $F_{(1,196)}=8.14$, $P=0.019$ ) and (iii) the group with the lowest health tolerance, sticklebacks infected with warm-origin parasites at $24{ }^{\circ} \mathrm{C}$ (lower red line; $F_{(1,196)}=38.20, P<0.001$ ). Furthermore, health tolerance of sticklebacks kept at the warm experimental temperature was significantly increased when infected with parasites from the cold origin (lower blue line in Fig. 5) compared to those infected with parasites from the warm origin (lower red line; $\left.F_{(1,196)}=15.43, P=0.001\right)$. In contrast, fecundity tolerance measured using host gonad weight as a response variable, did not differ across treatments. Similarly, we found no effect of sympatry/allopatry on health or fecundity tolerance (Additional file 1: Table S3).

\section{Discussion}

The warm experimental temperature used in the present study, promoted the growth of S. solidus, which is a correlate for parasite fecundity and fitness $[15,16]$. In contrast, the ectothermic stickleback host exhibited higher fitness, measured as growth rate and gonad development, at the cooler experimental temperature. Moreover, warm conditions down-regulated stickleback immunity, i.e. the number of head kidney leukocytes (HKLs), especially in response to parasite infection, and the respiratory burst activity. Warm conditions even seemed to be detrimental to sticklebacks since host mortality was elevated at the warm experimental temperature. Altogether, these observations suggest that host fitness decreases and parasite fitness increases with rising temperature, the latter could be due to a combination of a higher parasite metabolic rate, and also because of a less efficient host immune response.

When infected with cold-origin S. solidus, sticklebacks from the cold origin grew faster than those from the warm origin, suggesting adaptations of the host to the local parasite genotype. However, contrary to our expectations we did not find further evidence for mutual adaptations between local host-parasite pairs but both hosts and parasites showed signs of adaptations to the temperature in their habitat of origin. This is illustrated by sticklebacks from the cold site of Lake Mývatn growing faster and showing higher plasticity in their leukocyte responses towards $S$. solidus infection than their conspecifics from the warm

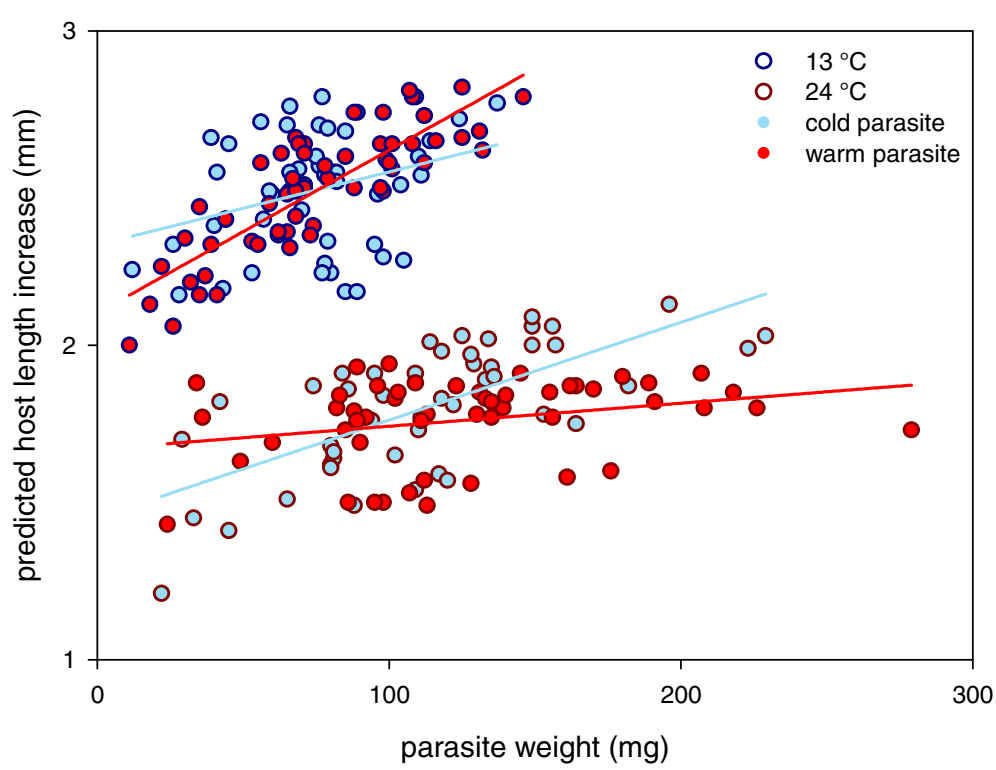

Fig. 5 Host health tolerance. The interaction between experimental temperature $\left(13\right.$ or $24^{\circ} \mathrm{C}$ ), parasite origin (cold or warm) and parasite weight $\left(F_{(1,177)}=6.72, P=0.010\right)$, indicates variation in health tolerance. Steeper positive slopes of the linear relationship between host length increase and parasite weight indicate greater health tolerance. Values for host length increase are model predictions from Box-Cox transformed data and not congruent with the values from Fig. 1a 
origin. Previous studies have revealed that experimentally cold-adapted three-spined sticklebacks had faster growing offspring compared to conspecifics that were experimentally warm adapted, illustrating that temperature might cause transgenerational plasticity [31-33]. The present study used offspring from parents collected from warm and cold environments, thus the observed temperature adaptations might be due to transgenerational effects.

Millet et al. [6] demonstrated that sticklebacks sampled at warm and cold sites of Lake Mývatn differed phenotypically, but showed little genetic variation. They suggested that Mývatn sticklebacks show relatively broad phenotypic plasticity and explained the lack of genetic divergence by the existence of gene flow across the lake and the relatively young age of the Mývatn stickleback population. Given that there is a lack of genetic divergence in the study population, signs of temperature adaptation described in the present study, might be based on transgenerational plasticity of temperature adaptation.

Temperature adaptations were also found for the parasite. Schistocephalus solidus was capable of exploiting its host more efficiently at its temperature of origin, suggested by lower health tolerance of infected sticklebacks at the parasite's temperature of origin. In contrast, the health tolerance of sticklebacks was higher when infected with parasites at the parasite's 'foreign' temperature. Thus the present study suggests adaptation of the parasites to their local temperature, which has costs for their hosts. However, in comparison to the differences provoked by the cold and the warm experimental temperatures, the signs of local temperature adaptation were relatively subtle, suggesting that the current environmental conditions have a greater impact on host physiology than genetic or somatic contributions from the parents. In contrast to the observed effect of parasite origin on host health tolerance, hosts from different origins did not differ in health tolerance, neither in fecundity tolerance. Similarly, we found no variation in fecundity tolerance, nor did we find an effect of sympatry/allopatry on host tolerance. In the wild, transition of parasites from their adaptive temperature to a 'foreign' temperature regime might result in relatively higher host tolerance, suggesting that intruding parasites cause lower host fitness reduction compared to sympatric coevolved ones. Given that the final host of S. solidus is a bird, there would be ample opportunities for the dispersion of the parasite. In global warming scenarios, increased host fitness costs due to predicted higher parasite life-cycle completion and dispersal rates [46], could be compensated for, at least to some extent by host tolerance. There is an increasing appreciation of the importance of abiotic factors on host tolerance [24]. Recently, it was described that Drosophila melanogaster infected with a fungus seek cooler temperatures, under which they were able to increase resistance to the fungal infection and increase their late life reproductive output [59]. Temperature preferences were not tested in the present study, but our data suggest that seeking of cooler temperature would also benefit sticklebacks infected with $S$. solidus, since parasites would grow less, while hosts could invest more in immunity, growth and fecundity.

Sticklebacks that were exposed to $S$. solidus but did not develop an infection at $13{ }^{\circ} \mathrm{C}$, had increased numbers of HKLs compared to sham-exposed controls, which is intriguing since it means that an unsuccessful parasite infection left an imprint on the host immune system eight weeks after parasite exposure. The rejection of parasite larvae likely occurred during the first 2 weeks after infection [37], consequently we did not observe any parasite residuals in the host body cavity. It is possible that parasite antigens were still present in the exposed but not infected sticklebacks, which triggered the immune system, but interestingly increased numbers of HKLs in exposed but not infected sticklebacks were only observed at $13{ }^{\circ} \mathrm{C}$, the more optimal temperature for the host.

\section{Conclusions}

The present study demonstrates that $S$. solidus parasites benefit from warmer temperatures, whereas the fitness and immunity of their stickleback hosts are generally higher in the cold. This strongly suggests that temperature variation interferes with fitness trade-offs in host-parasite interactions, in addition to interfering with host health tolerance to $S$. solidus infection. However, both hosts and parasites were plastic in their responses to temperature and at least the plasticity of the host seems to be transgenerational mediated.

\section{Additional file}

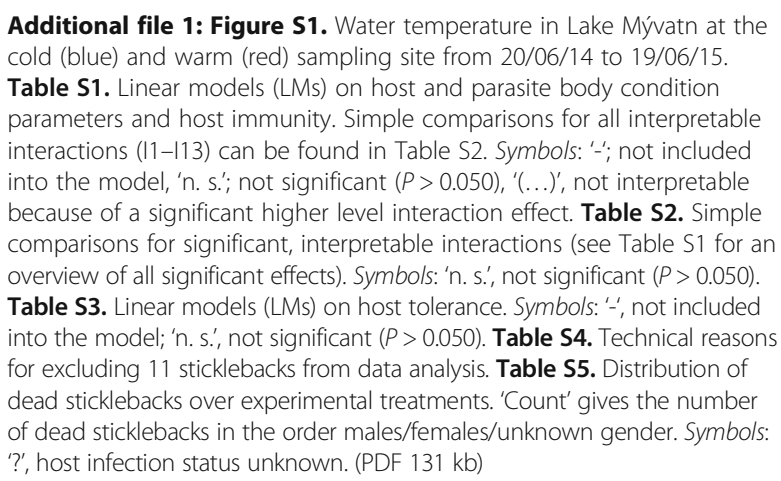

\section{Abbreviations}

FACS: Fluorescence accelerated cell scanner; GLM: Generalized linear model; HEPES: 2-[4-(2-hydroxyethyl) piperazin-1-yl] ethanesulfonic acid; HKL: Head kidney leukocyte; LM: Linear model; MEM: Minimal essential medium; MS222: Ethyl 3-aminobenzoate methanesulfonate; R-90: RPMI-1640 with

$10 \mathrm{mmol} \mathrm{I}^{-1}$ HEPES and 10\% v/v distilled water; RLU: Relative luminescence unit; RPMI-1640: Roswell Park Memorial Institute cell culture medium no. 1640; YG: yellow, green 


\section{Acknowledgements}

We are grateful to B. K. Kristjánsson and Á. Einarsson (Holar University College, Iceland) for enabling stickleback catching in Lake Mývatn. We thank I. Rauch, B. Hasert, L. Grotendorst, M. Hamley, A. M. Wohlleben, B. Wieczorek, J. Lange, W. Niermann and G. Plenge for technical assistance and support in the maintenance of the experimental sticklebacks. We thank two anonymous reviewers for their constructive comments on the manuscript. The project was funded by the German Research Foundation (DFG) within the Priority Programme SPP 1399 on Host-Parasite Coevolution, project number SCHA-1257/2-2 to JPS and AR 872/1-1 to SAOA.

\section{Funding}

The project was funded by the DFG grant to J. P. Scharsack (SCHA 1257/2-2) and to SAO Armitage (AR 872/1-1).

\section{Availability of data and materials}

The data supporting the conclusions of this article are included within the article. Raw data analysed during the study are available from the corresponding author on reasonable request.

\section{Authors' contributions}

FF designed the study, performed the field and laboratory work, carried out the data analyses and drafted the manuscript. MAMK and SAOA participated in the data analysis and manuscript editing. JK gave advice on the study design and participated in manuscript editing. JPS conceived and coordinated the study, performed the field and laboratory work, participated in statistical analyses and manuscript editing. All authors read and approved the final manuscript.

\section{Competing interests}

The authors declare that they have no competing interests.

\section{Consent for publication}

Not applicable.

\section{Ethics approval and consent to participate}

Sticklebacks were maintained and treated in accordance with the local animal welfare authorities and the EU Directive 2010/63/EU for animal experiments. All animal experiments described were approved by the 'State Agency for Nature, Environment and Consumer Protection' (LANUV) of North Rhine Westphalia, Germany (reference number: 87-51.04.2010.A297).

\section{Publisher's Note}

Springer Nature remains neutral with regard to jurisdictional claims in published maps and institutional affiliations.

Received: 25 January 2017 Accepted: 11 May 2017 Published online: 02 June 2017

\section{References}

1. Ferguson HM, Read AF. Genetic and environmental determinants of malaria parasite virulence in mosquitoes. Proc R Soc Lond B. 2002;269:1217-24.

2. Blanford S, Thomas M, Pugh C, Pell J. Temperature checks the Red Queen? Resistance and virulence in a fluctuating environment. Ecol Lett. 2003;6:2-5.

3. Linder JE, Owers KA, Promislow DEL. The effects of temperature on hostpathogen interactions in D. melanogaster: Who benefits? I Insect Physiol. 2008;54:297-308

4. Kaltz O, Shykoff JA. Local adaptation in host-parasite systems. Heredity. 1998;81:361-70.

5. Kawecki TJ, Ebert D. Conceptual issues in local adaptation. Ecol Lett. 2004:7: $1225-41$.

6. Millet A, Kristiánsson BK, Einarsson Á, Räsänen K. Spatial phenotypic and genetic structure of threespine stickleback (Gasterosteus aculeatus) in a heterogeneous natural system, Lake Mývatn, Iceland. Ecol Evol. 2013;3:3219-32.

7. Karvonen A, Kristjánsson BK, Skúlason S, Lanki M, Rellstab C, Jokela J. Water temperature, not fish morph, determines parasite infections of sympatric Icelandic threespine sticklebacks (Gasterosteus aculeatus). Ecol Evol. 2013;3: 1507-17.

8. Arme C, Owen RW. Infections of the three-spined stickleback, Gasterosteus aculeatus L., with the plerocercoid larvae of Schistocephalus solidus (Müller, 1776), with special reference to pathological effects. Parasitology. 1967:57: 301-14.
9. Pennycuick $L$. Seasonal variations in parasite infections in a population of three-spined sticklebacks, Gasterosteus aculeatus L. Parasitology. 1971;63: 373-88.

10. Tierney JF, Huntingford FA, Crompton DWT. Body condition and reproductive status in sticklebacks exposed to a single wave of Schistocephalus solidus infection. J Fish Biol. 1996:49:483-93.

11. Bagamian KH, Heins DC, Baker JA. Body condition and reproductive capacity of three-spined stickleback infected with the cestode Schistocephalus solidus. J Fish Biol. 2004:64:1568-76.

12. Heins DC. Fecundity compensation in the three-spined stickleback Gasterosteus aculeatus infected by the diphyllobothriidean cestode Schistocephalus solidus. Biol J Linnean Soc. 2012;106:807-19.

13. Giles N. Behavioral effects of the parasite Schistocephalus solidus (Cestoda) on an intermediate host, the three-spined stickleback, Gasterosteus aculeatus. Anim Behav. 1983:31:1192-4.

14. Barber I, Huntingford FA. The effect of Schistocephalus solidus (Cestoda: Pseudophyllidea) on the foraging and shoaling behaviour of three-spined sticklebacks, Gasterosteus aculeatus. Behaviour. 1995;132:1223-40.

15. Wedekind C, Strahm D, Schärer L. Evidence for strategic egg production in a hermaphroditic cestode. Parasitology. 1998;117:373-82.

16. Dörücü $M$, Wilson D, Barber I. Differences in adult egg output of Schistocephalus solidus from singly- and multiply-infected sticklebacks. J Parasitol. 2007:93:1521-3.

17. Franke F, Rahn AK, Dittmar J, Erin N, Rieger JK, Haase D, et al. In vitro leukocyte response of three-spined sticklebacks (Gasterosteus aculeatus) to helminth parasite antigens. Fish Shellfish Immunol. 2014;36:130-40.

18. Kalbe M, Eizaguirre C, Scharsack JP, Jakobsen PJ. Reciprocal cross infection of sticklebacks with the diphyllobothriidean cestode Schistocephalus solidus reveals consistent population differences in parasite growth and host resistance. Parasit Vectors. 2016:9:130.

19. Råberg L, Sim D, Read AF. Disentangling genetic variation for resistance and tolerance to infectious diseases in animals. Science. 2007:318:812-4.

20. Råberg L, Graham AL, Read AF. Decomposing health: tolerance and resistance to parasites in animals. Phil Trans $\mathrm{R}$ Soc Lond $\mathrm{B}$. 2009;364:37-49.

21. Sternberg ED, Li H, Wang R, Gowler C, De Roode JC. Patterns of hostparasite adaptation in three populations of monarch butterflies infected with a naturally occurring protozoan disease: virulence, resistance, and tolerance. Amer Nat. 2013;182:E235-48.

22. Feis ME, Goedknegt MA, Thieltges DW, Buschbaum C, Wegner KM. Biological invasions and host-parasite coevolution: different coevolutionary trajectories along separate parasite invasion fronts. Zoology. 2016;119:366-74.

23. Kutzer MAM, Armitage SAO. The effect of diet and time after bacterial infection on fecundity, resistance, and tolerance in Drosophila melanogaster. Ecol Evol. 2016;6:4229-42.

24. Kutzer MAM, Armitage SAO. Maximising fitness in the face of parasites: a review of host tolerance. Zoology. 2016;119:281-9.

25. Ebert D, Carius HJ, Little T, Decaestecker E. The evolution of virulence when parasites cause host castration and gigantism. Amer Nat. 2004;164:S19-32.

26. Heins D, Ulinski B, Johnson J, Baker J. Effect of the cestode macroparasite Schistocephalus pungitii on the reproductive success of ninespine stickleback, Pungitius pungitius. Can J Zool. 2004;82:1731-7.

27. Jackson JA, Hall AJ, Friberg IM, Ralli C, Lowe A, Zawadzka M, et al. An immunological marker of tolerance to infection in wild rodents. PLOS Biol. 2014:12, e1001901.

28. Hayward AD, Nussey DH, Wilson AJ, Berenos C, Pilkington JG, Watt KA, et al. Natural selection on individual variation in tolerance of gastrointestinal nematode infection. PLoS Biol. 2014;12, e1001917.

29. Anaya-Rojas JM, Brunner FS, Sommer N, Seehausen O, Eizaguirre C, Matthews B. The association of feeding behavior with the resistance and tolerance to parasites in recently diverged sticklebacks. J Evol Biol. 2016;29: 2157-67.

30. Dittmar J, Janssen H, Kuske A, Kurtz J, Scharsack JP. Heat and immunity: an experimental heat wave alters immune functions in three-spined sticklebacks (Gasterosteus aculeatus). J Anim Ecol. 2014;83:744-57.

31. Shama LNS, Strobel A, Mark FC, Wegner KM. Transgenerational plasticity in marine sticklebacks: maternal effects mediate impacts of a warming ocean. Funct Ecol. 2014:28:1482-93.

32. Shama LNS, Wegner KM. Grandparental effects in marine sticklebacks: transgenerational plasticity across multiple generations. J Evol Biol. 2014;27: 2297-307. 
33. Shama LNS, Mark FC, Strobel A, Lokmer A, John U, Mathias Wegner K. Transgenerational effects persist down the maternal line in marine sticklebacks: gene expression matches physiology in a warming ocean. Evol Appl. 2016;10.1111/eva.12370.

34. Barber I, Berkhout BW, Ismail Z. Thermal change and the dynamics of multihost parasite life cycles in aquatic ecosystems. Integr Comp Biol. 2016;56: 561-72

35. Roessig JM, Woodley CM, Cech JJ, Hansen LJ. Effects of global climate change on marine and estuarine fishes and fisheries. Rev Fish Biol Fish. 2004;14:251-75.

36. Leicht K, Seppälä O. Infection success of Echinoparyphium aconiatum (Trematoda) in its snail host under high temperature: role of host resistance. Parasit Vectors. 2014;7:192.

37. Scharsack JP, Koch K, Hammerschmidt K. Who is in control of the stickleback immune system: interactions between Schistocephalus solidus and its specific vertebrate host. Proc R Soc Lond B. 2007;274:3151-8.

38. Evans NA. The influence of environmental temperature upon transmission of the cercariae of Echinostoma liei (Digenea, Echinostomatidae). Parasitology. 1985;90:269-75.

39. Shostak AW, Esch GW. Photocycle dependent emergence by cercariae of Halipegus occidualis from Helisoma anceps, with special reference to cercarial emergence patterns as adaptations for transmission. J Parasitol. 1990;76:790-5.

40. Paull SH, Raffel TR, LaFonte BE, Johnson PTJ. How temperature shifts affect parasite production: testing the roles of thermal stress and acclimation. Funct Ecol. 2015;29:941-50.

41. Studer A, Thieltges DW, Poulin R. Parasites and global warming: net effects of temperature on an intertidal host-parasite system. Mar Ecol Prog Ser. 2010;415:11-22.

42. Lv S, Zhou X, Zhang Y, Liu H, Zhu D, Yin W, et al. The effect of temperature on the development of Angiostrongylus cantonensis (Chen 1935) in Pomacea canaliculata (Lamarck 1822). Parasitol Res. 2006;99:583-7.

43. Tokeson JPE, Holmes JC. The effects of temperature and oxygen on the development of Polymorphus marilis (Acanthocephala) in Gammarus lacustris (Amphipoda). J Parasitol. 1982;68:112-9.

44. Wegner KM, Kalbe M, Milinski M, Reusch TBH. Mortality selection during the 2003 European heat wave in three-spined sticklebacks: effects of parasites and MHC genotype. BMC Evol Biol. 2008:8:124.

45. Schade FM, Shama LNS, Wegner KM. Impact of thermal stress on evolutionary trajectories of pathogen resistance in three-spined stickleback (Gasterosteus aculeatus). BMC Evol Biol. 2014;14:164.

46. Macnab V, Barber I. Some (worms) like it hot: fish parasites grow faster in warmer water, and alter host thermal preferences. Global Change Biol. 2012; 18:1540-8.

47. Barber I, Split-clutch AS, IVF. A technique to examine indirect fitness consequences of mate preferences in sticklebacks. Behaviour. 2000;137: 1129-40.

48. Lüscher A, Milinski M. Simultaneous hermaphrodites reproducing in pairs self-fertilize some of their eggs: an experimental test of predictions of mixed-mating and Hermaphrodite's Dilemma theory. J Evol Biol. 2003;16: 1030-7.

49. Smyth JD. Studies on tapeworm physiology. VII. Fertilization of Schistocephalus solidus in vitro. Exp Parasitol. 1954;3:64-71.

50. Schärer $\mathrm{L}$, Wedekind $\mathrm{C}$. Lifetime reproductive output in a hermaphrodite cestode when reproducing alone or in pairs: a time cost of pairing. Evol Ecol. 1999;13:381-94.

51. Tierney JF, Crompton DWT. Infectivity of plerocercoids of Schistocephalus solidus (Cestoda, Ligulidae) and fecundity of the adults in an experimental definitive host, Gallus gallus. J Parasitol. 1992;78:1049-54.

52. Scharsack JP, Kalbe M, Harrod C, Rauch G. Habitat-specific adaptation of immune responses of stickleback (Gasterosteus aculeatus) lake and river ecotypes. Proc R Soc Lond B. 2007;274:1523-32.

53. Scharsack JP, Kalbe M, Derner R, Kurtz J, Milinski M. Modulation of granulocyte responses in three-spined sticklebacks Gasterosteus aculeatus infected with the tapeworm Schistocephalus solidus. Dis Aquat Organ. 2004; 59:141-50.

54. Pechhold K, Pohl T, Kabelitz D. Rapid quantification of lymphocyte subsets in heterogeneous cell populations by flow cytometry. Cytometry. 1994;16:152-9.

55. Scott AL, Klesius PH. Chemiluminescence: a novel analysis of phagocytosis in fish. Dev Biol Stand. 1981:49:243-54.
56. Kurtz J, Kalbe M, Aeschlimann PB, Häberli MA, Wegner KM, Reusch TBH. Major histocompatibility complex diversity influences parasite resistance and innate immunity in sticklebacks. Proc R Soc Lond B. 2004;271:197-204.

57. Tiffin $\mathrm{P}$, Inouye B. Measuring tolerance to herbivory: Accuracy and precision of estimates made using natural versus imposed damage. Evolution. 2000; 54:1024-9.

58. Babyak M. What you see may not be what you get: A brief, nontechnical introduction to overfitting in regression-type models. Psychosom Med. 2004;66:411-21.

59. Hunt VL, Zhong W, McClure CD, Mlynski DT, Duxbury EML, Charnley AK, Priest NK. Cold-seeking behaviour mitigates reproductive losses from fungal infection in Drosophila. J Anim Ecol. 2016;85:178-86.

\section{Submit your next manuscript to BioMed Central and we will help you at every step:}

- We accept pre-submission inquiries

- Our selector tool helps you to find the most relevant journal

- We provide round the clock customer support

- Convenient online submission

- Thorough peer review

- Inclusion in PubMed and all major indexing services

- Maximum visibility for your research

Submit your manuscript at www.biomedcentral.com/submit
Biomed Central 